\title{
Ian Bekker and Erez Levon* \\ The embedded indexical value of /s/-fronting in Afrikaans and South African English
}

https://doi.org/10.1515/ling-2017-0022

Abstract: This paper examines the indexical value of /s/-fronting in White Afrikaans and in White South African English (WSAfE). Prior research on this feature has shown that fronted articulations of /s/ in WSAfE serve as a regional and social indicator of the wealthy northern suburbs of Johannesburg, and anecdotal evidence suggests that the feature carries a similar meaning in White Afrikaans. This study therefore aims to examine whether the variable carries similar meanings across the two languages. Data are based on the evaluative reactions toward different experimental stimuli that were presented to 214 Afrikaans-English bilinguals in South Africa during a modified matchedguise task. The results indicate that /s/-fronting in a man's voice is perceived in similar terms in White Afrikaans and WSAfE though it carries somewhat different meanings across the two languages when it occurs in a woman's voice, a difference related in turn to different approaches to gender across the two speech communities. The results of this research, and the indexical value of /s/-fronting in the two languages, are therefore only understandable in terms of certain sociohistorical and sociological differences between the two speech communities. The article ends with some discussion relating to the possible source of the relevant similarities and differences, i.e., parallel innovation or sociophonetic transfer.

Keywords: /s/-fronting, Afrikaans, White South African English, perception, South Africa

\section{Introduction}

There is much research showing that fronted-/s/, i.e., /s/ with a dental or dentialveolar place of articulation, when used by men generally indexes being gay or

\footnotetext{
*Corresponding author: Erez Levon, Department of Linguistics, Queen Mary, University of London, Mile End Road, London E1 4NS, UK, E-mail: e.levon@qmul.ac.uk Ian Bekker, School of Languages, North-West University, Internal Box 493, Private Bag X6001, Potchefstroom Campus, Potchefstroom 2520, South Africa, E-mail: Ian.Bekker@nwu.ac.za
} 
at least decreased masculinity (e.g., Zimman 2013; Pharao et al. 2014). ${ }^{1}$ A similar judgment concerning its use by women also appears to be widespread, i.e., it cues some kind of construct of heightened femininity (e.g., Stuart-Smith 2007; Levon and Holmes-Elliott 2013). This appears to be the case more generally across both related and unrelated languages (a topic that many of the articles in this special issue address) and, more specifically, when it comes to a vast array of English varieties (in the US: Munson et al. 2006; Levon 2006; Campbell-Kibler 2011; Zimman 2013; in England: Levon 2014; in Scotland: Stuart-Smith 2007; and in New Zealand: Starks and Allan 2003). While no research has, as yet, been conducted on this matter within the South African context, White South African English (WSAfE), and the sociolectal continuum this label refers to, is almost certainly no exception to this general trend. ${ }^{2}$ What has been directly tested to date, however, is the use of fronted-/s/ as a regional (and social) indicator (Bekker 2007), above and beyond its use as an index of feminine prestige for at least some speakers of SAfE. The main finding of Bekker (2007) is that fronted-/s/ is more characteristic of the wealthy northern suburbs of Johannesburg than elsewhere, with the northern suburbs being clearly associated in the local South African English consciousness with wealth and prestige, albeit often of a nouveau riche kind. In this sense, the use of fronted-/s/ is thus arguably associated with the socalled kugel stereotype, which has traditionally indexed a young, white, often Jewish female with social ambitions (Lanham and Macdonald 1979) but which is now often simply associated more generally (although not exclusively) with the northern suburbs of Johannesburg. ${ }^{3}$ Given that this stereotype is associated with

1 The authors suspect that a similar quality can also be created by the use of lip-spreading, either replacing the tongue articulation, or in combination with it. The first author suspects that the use of lip-spreading is, in fact, common in certain varieties of South African English and Afrikaans.

2 The use of the term white is for obvious reasons a sensitive one in the South African context. Its use is retained for the simple reason that, while there are a growing number of non-white individuals who are using this dialect (Mesthrie 2010), they are still in the vast minority. Many of the divisions caused by apartheid are still, unfortunately, reflected in the fact that speakers of different dialects are still broadly distinguishable in terms of race or ethnicity.

One set of terms in the South African English (SAfE) literature describing this continuum is Broad SAfE, General SAfE and Cultivated SAfE. General SAfE is the local standard and the most widely spoken sociolect in the broader WSAfE speech community.

3 The term kugel is traditionally associated with the South African Jewish community, is usually used to refer to (materialistic) women and comes from a term referring to a traditional Ashkenazi Jewish dish. Thus according to the Wikipedia entry on this term, "Among South African Jews, the word "kugel" was used by the elder generation as a term for a young Jewish woman who forsook traditional Jewish dress values in favor of those of the ostentatiously 
more than just one linguistic variable, the study in Bekker (2007) was followed up by a similar study on the possible dentalization of other generally alveolar consonants (i.e., /t/, /d/ and /z/) among the same population group, with similar findings (O’Grady and Bekker 2011). ${ }^{4}$

Given the findings mentioned above on the seemingly general trend for high frequency sibilants to index some form of femininity, it would be surprising to find that Afrikaans - a Germanic language with a longer history in South Africa than English - did not exhibit similar characteristics, both in terms of evidence of the use of fronted-/s/ as well as evidence of an indexical value for this feature broadly consonant with that found in other languages. Furthermore, given that Afrikaans and English speakers in South Africa have a long history of contact on both a cultural and linguistic level, it would also be unsurprising if Afrikaans speakers exhibited indexically based value-judgments about the use of fronted /s/ in SAfE. The primary focus of the research reported in this article, therefore, is on determining the indexically based value judgments of a group of young, White L1-Afrikaans individuals, both male and female, towards fronted-/s/ in both Afrikaans and (South African) English and in both male and female speech. More generally, it will be interesting to see whether the indexical value of this feature differs for L1-Afrikaans speakers depending on whether it is used in English or Afrikaans (and, again, taking the gender of the speaker into account). A lack of difference across the two languages could point to either a universalist, sound-symbolic basis (Ohala 1994) for the use of fronted /s/ in both WSAfE and White Afrikaans, or to the possibility of a sociophonetic transfer of sorts, i.e., the borrowing of a phonetic feature and perhaps its indexical value from one language to another. Differences in the indexical values cued for Afrikaans

wealthy, becoming overly materialistic and over groomed, the kugel being a plain pudding garnished as a delicacy. The women thus described made light of the term and it has since become an amusing rather than derogatory slang term in South African English, referring to a materialistic young woman" [accessed on 24/02/2016]. Still, the history and, most importantly, the full indexical range of this stereotype still requires serious research; while it clearly exists, its exact range and meaning is unclear, particularly given that it has clearly been extended more recently to outside the South African Jewish community. This research, we believe, takes a first step in this direction. While the perceptions of Afrikaans-speakers might differ somewhat from those of English-speakers, we believe the results captured in this research reflect at least one valid (and relatively widespread) view of this stereotype.

4 The most common and stereotyped feature is that of fronted PRICE monophthongization, i.e., the use of [a:] for /ai/. Unlike in the Canadian Shift, this quality is not conditioned by the following consonant. As pointed out correctly by an anonymous reviewer, PRICE-monophthongization has for long been associated with the kugel stereotype in Johannesburg and it is quite possible that /s/-fronting is, on this basis, more characteristic of younger female as opposed to older female speakers of this variety. 
speakers by fronted-/s/ in English and Afrikaans could, in contrast, point to the interaction of factors specific to these two speech communities with the indexical value concerned. We will see below that many of the results can only be clearly understood if the sociocultural history of Afrikaans, and in particular Afrikaans-English relations in South Africa, are taken into account by way of explanatory background. A similar explanatory role is played by non-linguistic research on differences across the English and Afrikaans-speaking communities with respect to the maintenance (or not) of certain traditional gender roles and/ or perceptions of femininity.

The next section provides this sociohistorical and sociological background, focusing specifically on the general attitudes and relations, over time, of Afrikaans-speakers towards and with English and its speakers. As intimated above, it also looks at existing research on gender roles within the Afrikaansspeaking community. The section after that outlines the methods used, i.e., both the creation of the relevant stimuli and their application to a body of respondents. The last two sections provide an analysis and summary of the results.

\section{Sociohistorical background}

This section focuses briefly on two sociohistorical aspects which serve to inform the interpretation of the empirical results of this study: Afrikaans-English contact and relations in the South African context, and gender roles within the White South African, particularly Afrikaans, community. As has been stressed in Bekker (2003), historical data is often essential in fully understanding language attitudes.

\subsection{The history of Afrikaans-English contact and relations}

Any proper understanding of the attitudes of Afrikaans individuals towards English, South African English and specific variables within this dialect (such as /s/-fronting) needs to be informed by at least an outline of the complex history of the relationship between the English and Afrikaans groups in South Africa. This relationship is made even more complex by the fact that the term Afrikaner, in particular, needs to be clearly defined. This is a task made particularly irksome by, among other things, current debates concerning Afrikaner identity and culture.

As a first approximation, and stereotypically, the term Afrikaner is often reserved for L1-Afrikaans-speaking White individuals. It is clear therefore that the terms Afrikaans-speaking and Afrikaner are not synonymous given that the 
later term automatically excludes many L1-Afrikaans-speakers who were previously classified as Coloured during the apartheid regime. ${ }^{5}$ At the same time, there are a growing number of (particularly young) white individuals who would resist the label Afrikaner and would instead prefer the terms Afrikaans or Afrikaans-speaking. This is the result of an implicit association of the term Afrikaner with the form of racial-ethnic nationalism that saw its apotheosis during the apartheid regime of 1948 to 1990. Such Afrikaner nationalism has deep historical and social roots and attitudes towards it also overlap quite clearly with attitudes towards (White) South African L1-English-speakers, English (speakers) in general and South African English in particular, given the racial tensions of the South African past.

Afrikaner nationalism was, in fact, a direct result of British colonialism, which began in the late eighteenth-century, accelerating rapidly during the course of the nineteenth. British colonialism was, for one, responsible for the displacement of many Dutch/Afrikaans-speakers from the Cape, i.e., from the area that had previously been under Dutch control (Giliomee 2003). ${ }^{6}$ As can be seen from Figure 1, by the late nineteenth century, current-day South Africa was divided into two British Colonies (The Cape Colony and Natal), as well as two Boer Republics, the Zuid-Afrikaansche Republiek (Transvaal in Figure 1) and the Oranje-Vrijstaat (Orange Free State). ${ }^{7}$ These two Afrikaner republics had been set up during the course of the nineteenth century by so-called Voortrekkers (roughly 'pioneers') who, for various reasons, including attempts by the British Colonial Office to Anglicize the Afrikaans-speaking community in the Cape, were disenchanted with British colonial rule and had left the Cape Colony to found independent republics. By 1898 the two Boer Republics had already fended off the British during the First Anglo-Boer War (1880-1881) and were about to embark on a more extensive, but ultimately unsuccessful, effort to defend the republics from the British once again, i.e., the Second AngloBoer War (1899-1902). ${ }^{8}$

5 Unlike in the United States, the term Coloured was (and still is) used, in very general and over-simplified terms, to refer to an individual of mixed-race descent. Within the South African context it is not a derogatory term.

6 Afrikaans is arguably a Dutch creole.

7 Bechuanaland is basically present-day Botswana.

8 The term boer, originally meaning simply farmer, is now often used by non-Afrikaans-speakers (particularly African-language-speakers) in a somewhat derogatory sense to refer to a white Afrikaans-speaker in general or sometimes, more particularly, to a white Afrikaans-speaker that is, indeed, a farmer (such individuals being stereotypically more inclined to embrace some form of Afrikaner nationalism). The term is a highly imprecise one and its meaning depends very much on the individual using it as well as the context of use. 


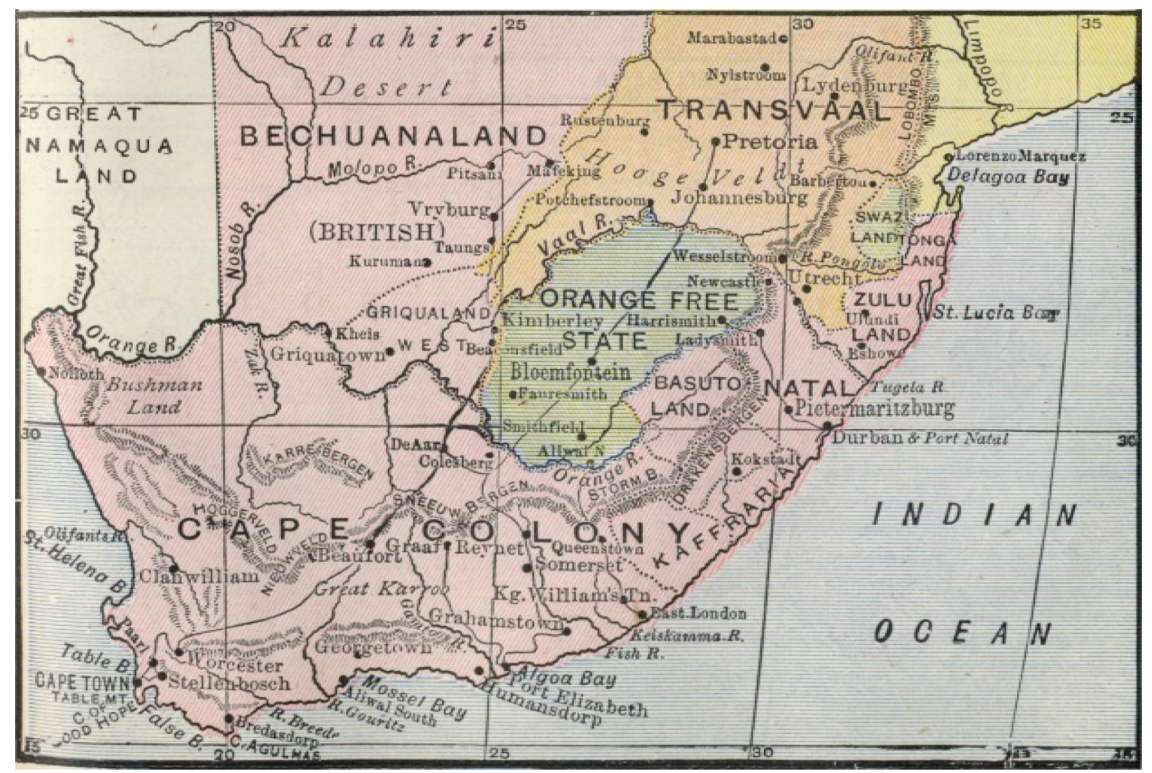

Figure 1: Map of South Africa ca. 1898.

At the cessation of hostilities the two former independent republics became British colonies, with all four colonies eventually becoming separate provinces of the Union of South Africa in 1910. From Union until 1948, politics in South Africa, although exclusively white, was characterized broadly by a degree of rapprochement between the English-cum-British (locally and more generally) and the (white) Afrikaans-speaking population. Thus, for example, a number of prominent Afrikaner politicians of the time (Jan Smuts and Louis Botha in particular) took an active part in World War I on the side of the British. In 1948, however, the political and social landscape changed dramatically with the success of the National Party in the general elections of that year. This political party not only ushered in the notorious system of apartheid, but was also actively involved in the promotion (and construction) of the Afrikaans identity, culture and language, and of Afrikaner nationalism more broadly.

Since 1990, however, the Afrikaans-speaking populations, both white and Coloured, have become (a) minority group(s) in the new, democratic South Africa. Since this time, Afrikaner and Afrikaans identity have been in a state of flux. ${ }^{9}$ As stressed by Davies (2009: 130), for example, "there has been a

9 We mean minority group in terms of power, not demographics; in terms of numbers the Afrikaner or Afrikaans-speaker has always been in the minority. The use of this term should 
paradigm shift in the political economic context of identifications among Afrikaans speakers in South Africa. A wide range of factors informs contemporary Afrikaner identifications". In short, the clear past connection between Afrikaner nationalist identity and contemporary Afrikaans social identity has been eroded.

The brief historical sketch above provides some idea of the complex relationship that (white) Afrikaans-speaking people have had vis-a-vis their White English counterparts. There is, of course, clear evidence of antagonism between these two populations, as is evidenced by the early- nineteenth century exodus of Voortrekkers from the Cape Colony, the two Anglo-Boer Wars and the rise of Afrikaner nationalism (with a distinct emphasis on the status and development of Afrikaans) for much of the twentieth century. Anecdotally, there are still Afrikaners alive today whose parents or grandparents died in the concentration camps set up by the British for Afrikaner women and children in the later periods of the Second Anglo-Boer War; and derogatory terms for English-speakers, like rooinek and soutpiel still have a degree of currency, particularly among the older generations. ${ }^{10}$

Nevertheless, there is also a long history of different forms of mixing between these two groups. On a very basic level, there are certain periods and places in South African history characterized by a high-degree of inter-marriage and bilingualism. These include the relationships between the so-called 1820 British settlers and Afrikaners who had already settled on the eastern frontier of the Cape Colony. ${ }^{11}$ Another locus for Afrikaans-English mixing were certain (generally lower-class) areas of early Johannesburg (established in 1886) which were characterized by a high degree of English-Afrikaans bilingualism. More generally, there have always been a sizeable number of Afrikaners who have maintained a positive or at least neutral attitude towards the English language. Right from the beginning of British colonialism, an ability to competently use English has been associated with prestige, urban-ness and education, and, for some, with generally enlightened values. As already intimated above with respect to Jan Smuts and Louis Botha, many prominent white Afrikaans

also not obfuscate the fact that, in general, Afrikaners are still relatively advantaged economically and culturally, as is the case with white individuals in South Africa generally.

10 Rooinek literally means red-neck and is a reference to the pale British soldiers during the Anglo-Boer Wars who had a tendency to get sunburned on the back of their necks during campaigns. Soutpiel means salt-dick. The idea here is that the person has one foot in Africa and one foot in England, with a certain appendage hanging in the Atlantic.

11 The first substantial body of British individuals who came to stay in South Africa; they disembarked in the winter of 1820 in Algoa Bay (see Figure 1). 
individuals have embraced the English-speaking world. Thus from a literary perspective, there are a host of Afrikaners who are, to this day, well-known for their ability to (and/or predisposition towards) writing in English (e.g., Herman Charles Bosman, Eugene Marais, Lourens van der Post and Andre P. Brink). This relatively open attitude towards English, often associated with openness towards globalization, the Western world etc., has only accelerated in postapartheid South Africa, with Afrikaans-English bilingualism among young people being the almost exceptionless norm. On the other hand, there remains a countervailing tendency within the Afrikaans community: "there is certainly considerable empirical evidence as to the emergence and nature of a new cultural politics ... involved in the preservation of an evolving Afrikaans language and culture" (Davies 2009: 134). It is worth mentioning in this regard that the university attended by the respondents of the current study has also become a recent site of Afrikaans politico-cultural struggle. As argued by Giliomee (2003: 658), "soon after the transition in 1994 the new government claimed that Afrikaans was used as a language to retain 'apartheid-style racial exclusivity", The Potchefstroom Campus of the North-West University, while technically multilingual, has, in practice, retained a mostly Afrikaans-focused approach to tuition, a fact that has very recently come under criticism from the ANC-led South African government; criticism which has, in turn, provoked, in some (white) Afrikaans quarters, including among many of the relevant university's students, a rather vitriolic reaction.

\subsection{Patriarchy and gender-roles within the Afrikaans and English speech communities}

In general, South Africa has been and still is a highly patriarchal and sexist society. There are, however, important internal differences. As in the case of politics, and at the risk of overgeneralizing, there has been a tendency for English-speaking South Africans to adopt a more liberal attitude towards gender roles. $^{12}$ White Afrikaans-speakers have, at least in the past, generally adopted a more conservative approach and McClintock (1993) has, for one, proposed a clear connection between Afrikaner nationalism and high degrees of patriarchy:

... the invention of Afrikaner tradition had a clear gender component. In 1918, a small, clandestine clique of Afrikaans men launched a secret society, with the express mission of

12 Although the general construction of gender in this community, as in the rest of the Western world, remains a basically patriarchal one cf. Pienaar and Bekker (2006; 2007). 


\begin{abstract}
capturing the loyalties of dispirited Afrikaners and fostering white male business power. The tiny white brotherhood swiftly burgeoned into a secret, country-wide mafia that came to exert enormous power over all aspects of Nationalist policy ... The gender bias of the society, as of Afrikanerdom as a whole, is neatly summed up in its name: the Broederbond (the brotherhood). Henceforth, Afrikaner nationalism would be synonymous with white male interests, white male aspirations and white male politics. Indeed, in a recent effort to shore up its waning power, the Broederbond is currently debating whether to admit socalled "Coloured" Afrikaans speaking men into the brotherhood. All women will, however, continue to be barred. (McClintock 1993: 68)
\end{abstract}

While the transition to a democratic society in 1994 challenged traditional gender roles in South Africa across the board, a recent study by Pretorius (2013), which provides an analysis of the visual representation of masculinities in a popular Afrikaans magazine, shows clearly that Afrikaans-speaking South Africa remains predominantly hetero-normative. The author's main finding is that, although things have changed marginally in the new South Africa, overall, "along with gay masculinity, black masculinity is marginalized, as are other non-conformist masculinities, including 'hybrid' South African masculinities and rebels" (Pretorius 2013: 228). While the study focuses mainly on masculinities, it briefly mentions the representation of women as well:

Most women are young and mooi [pretty], have long hair, are heavily made up and wear dresses. Hammond (2010: 12) uses the term "vanilla sexuality" to refer to this type of "perfectly styled sexuality that models hetero-normative Afrikaans femininity". Du Pisani's (2001: 161-162) comment that "feminism never really gained a foothold in Afrikaner society because of the strong grip of patriarchy, puritanism and authoritarianism" appears to hold true with regard to the visual representation of femininity in the magazine, in which female singers are presented as stereotypes who perform in accordance with hetero-normative gender roles. (Pretorius 2013: 227)

It seems clear enough therefore that the (white) Afrikaner female stereotype remains a relatively conservative one, and one which appears (intuitively at least) to be less liberal than that generally associated with women in the South African English-speaking community.

\title{
3 Method
}

With the aforementioned as background, we now turn to the investigation of L1 Afrikaans speakers' reactions to /s/-fronting in both English and Afrikaans. To achieve this task, we designed a modified matched-guise task (Lambert et al. 
1960; Levon 2006; Campbell-Kibler 2007). Two balanced Afrikaans/English bilinguals (one woman, one man) ${ }^{13}$ were recorded in a quiet room reading a stimulus passage in White Afrikaans and in White South African English (see Appendix A). The speakers were in their twenties at the time of recording and were postgraduate students at the North-West University, Potchefstroom, South Africa. Both are white L1 Afrikaans speakers who began acquiring English by the age of one and were judged by the first author to have native-like pronunciation in both languages. The Afrikaans passage was a short (40s) extract from the popular Afrikaans novel Kringe in ' $n$ bos (Matthee 1984), and the English passage was the corresponding extract taken from the book's English translation, Circles in a forest (Matthee 2005). The content of the passages is therefore controlled across languages, and both are written in a clear and accessible style. The Afrikaans version of the passage contains 30 tokens of /s/, while the English version contains 22. In both cases, /s/ is distributed across a variety of phrasal and phonological contexts (e.g., phrase-medial and phrase final; preceding both high-front and back-low vowels etc.). Recordings were made on a ICD-SX713 digital recorder using a lavalier microphone at a sampling frequency of 44,100 Hz. All recordings were scaled to an average intensity of $70 \mathrm{~dB}$ in an effort to reduce extraneous variation between speech samples.

Test stimuli for the matched-guise task were constructed by manipulating the recordings of both the English and Afrikaans versions of the passages. The speakers each read the passages twice, once with /s/ articulated as they normally would and then again after having been coached to produce a more sibilant or fronted pronunciation. ${ }^{14}$ Tokens of $/ \mathrm{s} /$ from the more fronted recordings were then cut and pasted into the speakers' original recordings to produce fronted versions of the stimuli. This allowed us to create fronted and non-fronted experimental guises for both speakers in both English and Afrikaans that were identical save for the quality of $/ \mathrm{s} /$. This is important since fronted articulations of /s/ can have obvious co-articulatory effects on adjacent segments which needed to be excluded from the stimuli in order to make sure that it was only the quality of /s/ that is responded to by listeners (Levon 2006; 2007; CampbellKibler 2007). Thus, in order to eliminate these additional co-articulatory effects, only the fronted /s/ itself was cut and pasted into the original recordings, ensuring that any differences observed in listener reactions to fronted versus non-fronted stimuli would be due to variation in /s/ quality and not some other confounding factor (e.g., vowel tensing or nasalization). While this method

13 The authors would like to thank Deon du Plessis and Kara Schultz in this regard and for assisting with the tabulation of results as well.

14 Both speakers have phonetic training. 
helps us to overcome the issue of potential co-articulation effects, it does, however, mean that stimuli in the fronted condition were not naturally produced whereas stimuli in the non-fronted condition were. In an effort to avoid any artificiality effects for fronted guises, the duration, average intensity and fundamental frequency of fronted variants were modified so as to match their nonfronted counterparts. In this way, naturally-produced non-fronted guises and manufactured fronted guises were as acoustically identical as possible, save for the target difference in /s/ spectral quality. ${ }^{15}$ All guises were, moreover, judged as sounding natural to both authors and a pre-test group of three listeners. We nevertheless acknowledge that despite these efforts, listeners may still be attuned to subtle naturalness differences between the guises above and beyond any reaction they have to differences in /s/-quality. Results must therefore be interpreted bearing this caveat in mind.

The manipulations of the original recordings resulted in the construction of eight experimental guises (2 languages $\times 2$ sexes $\times 2$ /s/ qualities) derived from two speakers. The average acoustic characteristics of $/ \mathrm{s} /$ for each of these guises are listed in Table 1. T-tests confirm significant differences in the expected direction (e.g., higher peak frequencies) of the acoustic characteristics of corresponding fronted versus non-fronted guises.

Table 1: Average Peak Frequency (Hz), Centre of Gravity (CoG; Hz) and Skewness of all /s/ tokens in the eight experimental guises.

\begin{tabular}{crrrrr}
\hline & \multicolumn{2}{c}{ Male Guises } & & Female Guises \\
\cline { 3 - 3 } & non-fronted & Fronted & & non-fronted & fronted \\
\hline Afrikaans guises & & & & \\
Peak & 4381.0 & 6459.8 & & 6304.5 & 7411.4 \\
CoG & 5372.1 & 7106.3 & & 6631.5 & 7725.9 \\
Skewness & 1.68 & 1.11 & & 1.26 & 0.87 \\
English guises & & & & \\
Peak & 5549.1 & 7409.6 & & 5950.5 & 8702.3 \\
CoG & 5936.5 & 7558.2 & & 6583.0 & 8363.8 \\
Skewness & 1.41 & 1.41 & & 1.64 & 0.49 \\
\hline
\end{tabular}

15 One characteristic we were unable to control for in fronted versus non-fronted guises was the structure and magnitude of formant transitions from the sibilant to neighboring vowels. Visual inspection of the formant transition structures between fronted and non-fronted guises does not reveal any obvious major differences, though we concede that we have not examined this feature in detail. 
The eight experimental stimuli along with four filler recordings of the same passages (1 man and 1 woman for both English and Afrikaans) ${ }^{16}$ were presented to 214 Afrikaans-English bilingual respondents. All respondents are South African, mother-tongue Afrikaans speakers with a moderate to high degree of proficiency in English. At the time of testing, all respondents were undergraduate students at the Potchefstroom Campus of the North-West University in South Africa. Given the population from which the respondents were drawn, there was little demographic variation within the sample. All respondents were relatively young (between 19-24 years old, mean age $=19.3$ ) and overwhelmingly white (97\% self-identified as either white or Afrikaner; the remaining 3\% all identified as Coloured). Seven respondents (3\%) reported speaking an additional language as a mother-tongue (i.e., bilingual from birth). For six of these individuals, that additional language is English while for the seventh it is German. In terms of gender, 128 of the respondents are women and 86 are men.

The respondent population were presented with the stimuli in groups (i.e., not individually) and in ambient listening conditions (i.e., not over headphones). There were 4 such groups and each group heard all twelve stimuli (8 experimental stimuli plus 4 fillers) with the order of presentation varying across groups (in 2 groups Block 1 was presented first while in the other 2 groups Block 2 was presented first; see Table 2). The order of presentation listed in Table 2 was designed so as to ensure maximum differentiation of language, speaker sex and

Table 2: Design of matched-guise experimental task.

\begin{tabular}{lllll}
\hline & Type & Language & Speaker sex & /s/-quality \\
\hline Block 1 & Filler & English & Male & $\mathrm{N} / \mathrm{A}$ \\
& Stimulus 1 & English & Female & non-fronted \\
& Stimulus 2 & Afrikaans & Male & fronted \\
& Filler & Afrikaans & Female & $\mathrm{N} / \mathrm{A}$ \\
& Stimulus 3 & English & Male & non-fronted \\
& Stimulus 4 & Afrikaans & Female & fronted \\
Block 2 & Filler & Afrikaans & Male & N/A \\
& Stimulus 1 & English & Female & fronted \\
& Stimulus 2 & Afrikaans & Male & non-fronted \\
& Filler & English & Female & N/A \\
& Stimulus 3 & English & Male & fronted \\
& Stimulus 4 & Afrikaans & Female & non-fronted \\
& & & &
\end{tabular}

16 The authors would like to thank Dayna Remus, Wynand Steyn and the 2015 third-year linguistics class at North-West University (Potchefstroom Campus) in this regard. 
/s/-quality between contiguous experimental stimuli. For example, stimulus 1 (English, female, non-fronted $/ \mathrm{s} /$ ) is maximally different from stimulus 2 (Afrikaans, male, fronted /s/), which immediately follows it. During the task, respondents rated each of the twelve stimuli (i.e, including the filler recordings) on eight evaluative scales (see Appendix B). These scales were designed to elicit listener judgments of various standard characteristics, including speaker status (intelligent/not intelligent; educated/not educated), likeability (friendly/not friendly; trustworthy/dishonest; laidback/not laidback), and perceived gender (masculine/not masculine), sexuality (gay-lesbian/not gay-lesbian) and region (lives in a city/lives in the country). After having rated all twelve recordings, respondents were asked to provide basic demographic information about themselves, including their age, sex, race/ethnicity and linguistic background. Responses to all aspects of the matched-guise task (evaluations of recordings, responses to demographic questions) were elicited entirely in Afrikaans, and all components of the response sheet (instructions, rating scales, etc.) were written in Afrikaans only.

\section{Findings}

Listeners' reactions to the eight experimental stimuli were subjected to linear mixed-effects regression analysis in $\mathrm{R}$. We examined responses to the female and male guises separately because we hypothesize that correlations between the rating scales will be different for the female-derived guises than for the malederived ones (e.g., we predict a positive correlation between perceived masculinity and perceived lesbianness, but a negative correlation between perceived masculinity and perceived gayness). In order to allow for more robust regression analysis, we first conducted preliminary Principal Components Analyses (with a varimax rotation) of responses to the female and male guises, using the principal function in the "psych" package in $\mathrm{R}$. This allowed us to reduce the eight rating scales to four and three dependent variables, respectively, for regression modelling (see Tables 3 and 4). ${ }^{17}$ For the female guises (Table 3), four principal components are identified. The first of these is characterized primarily by high factor loadings for perceived intelligence (0.82) and perceived level of education (0.80). There are additional weaker factor loadings for both friendliness (0.57) and honesty (0.46), but these traits also load on other identified components

17 The results listed in Tables 3 and 4 are based on an examination of responses to target experimental stimuli only (i.e., excluding fillers) and include both fronted and non-fronted guises. 
Table 3: Factor loadings and communalities for eight perceptual evaluation scales of women's voices (Method: Principal Components with varimax rotation).

\begin{tabular}{lrrrrr}
\hline & Status & Gender/Sexuality & Urban & Likeability & Communalities \\
\hline Intelligent & 0.82 & -0.12 & 0.08 & 0.00 & 0.69 \\
Friendly & 0.57 & -0.02 & -0.31 & 0.44 & 0.61 \\
Honest & 0.46 & -0.22 & -0.57 & -0.21 & 0.63 \\
Masculine & -0.18 & 0.77 & -0.17 & -0.12 & 0.68 \\
Urban & 0.32 & -0.05 & 0.77 & -0.14 & 0.72 \\
Gay/Lesbian & -0.03 & 0.81 & 0.22 & 0.04 & 0.71 \\
Educated & 0.80 & -0.09 & 0.16 & -0.01 & 0.68 \\
Laidback & -0.01 & -0.06 & 0.00 & 0.91 & 0.83 \\
Eigenvalue & 1.99 & 1.34 & 1.12 & 1.10 & \\
\% Variance & 0.25 & 0.17 & 0.14 & 0.14 & \\
Cumulative \% & 0.25 & 0.42 & 0.56 & 0.69 & \\
\hline
\end{tabular}

Table 4: Factor loadings and communalities for eight perceptual evaluation scales of men's voices (Method: Principal Components with varimax rotation).

\begin{tabular}{lrrrr}
\hline & Status & Gender/Sexuality & Likeability & Communalities \\
\hline Intelligent & 0.76 & 0.27 & 0.16 & 0.68 \\
Friendly & 0.21 & 0.14 & 0.65 & 0.48 \\
Honest & 0.21 & 0.55 & 0.16 & 0.37 \\
Masculine & 0.14 & 0.74 & -0.10 & 0.58 \\
Urban & 0.66 & -0.41 & -0.12 & 0.62 \\
Gay/Lesbian & 0.07 & -0.77 & 0.01 & 0.60 \\
Educated & 0.79 & 0.22 & 0.11 & 0.68 \\
Laidback & -0.07 & -0.11 & 0.82 & 0.70 \\
Eigenvalue & 1.76 & 1.76 & 1.19 & \\
\% Variance & 0.22 & 0.22 & 0.15 & \\
Cumulative \% & 0.22 & 0.44 & 0.59 & \\
\hline
\end{tabular}

and so it is difficult to interpret their precise contribution. We therefore associate this first component with a general perception of a speaker's status, as defined primarily by their perceived intelligence and education. The second component shows high loadings for perceived masculinity (0.77) and perceived lesbianness (0.81). We call this the gender/sexuality component. The third component is characterized primarily by a high loading for perceived urban-ness $(0.77)$ though 
there is an additional (negative) loading for perceived honesty ( -0.57$)$. Given the loading of the honesty dimension on multiple components, we treat the third component as principally defined by perceived region, though we note the correlation between being perceived as urban and being perceived as dishonest as an interesting and potentially meaningful pattern in our data. Finally, the fourth component loads very highly for perceptions of being laidback (0.91) with an additional weaker loading for perceived friendliness (0.44). We therefore term this fourth component the likeability component.

For men's guises (Table 4), only three components are identified, though the general structure parallels what is found for the female voices. The first component once again corresponds to perceptions of speaker status, with high loadings for both perceived intelligence (0.76) and education (0.79). Interestingly, there is an additional fairly high loading for perceptions of being urban (0.66), though this trait also negatively loads onto the second component. This second component is itself characterized by high loadings for perceived masculinity (0.74) and a negative loading for perceived gayness (-0.77). This gendered/ sexual meaning is supplemented by a fairly high loading for perceptions of honesty (0.55) as well as a negative loading for urban-ness (-0.41), as already mentioned. Taken together, this second component, which we label the gender/ sexuality component, appears to correspond to the image of a fairly traditional normative man (i.e., masculine, not gay, honest and rural). Finally, the third component, which we label likeability, shows high loadings for friendliness (0.65) and being laidback (0.82).

Factor scores were extracted for each component from the Principal Component Analyses presented in Tables 3 and 4 and used in subsequent regression modelling. We use factors scores in our regressions so as to maintain the full complexity of the observed factor structure. Regression models for each of the seven derived dependent variables (for female guises: status, gender/ sexuality, urban and likeability; for male guises: status, gender/sexuality and likeability), were manually stepped down from full models that included /s/fronting (fronted, non-fronted), language (Afrikaans, English), listener sex, order of presentation (Block 1 initial, Block 2 initial) and all interactions. Listener was included in all models as a random intercept. Order of presentation was never shown to have an effect, and so will not be discussed further. Below, we describe the results for each of the seven regression models in turn, before going on to discuss the ramifications of our findings. Regression models were built using the "Ime4" package in R, and p-values were obtained via Sattherthwaite approximations as implemented in the "lmerTest" package. Regression tables present the final models of the step-down process only that is, though all regressions began with maximal models (i.e., model with all 
predictors and all 2- and 3-way interactions) tables report results for models that contain only significant predictors or predictors that participate in significant interactions. In most cases, higher ratings in the tables correspond to an increased perception of the relevant component (i.e., increased perceived status, urban-ness and likeability). For the gender/sexuality components, higher ratings always correspond to greater perceived masculinity, and hence a more normative gender/sexuality for male guises (more masculine, less gay) but a more nonnormative one for female guises (more masculine, more lesbian).

\subsection{Female guises}

We begin with listener evaluations of female guises in terms of perceived status. In Table 5, we see that there is an overall main effect for language, such that listeners rate English guises as having significantly higher levels of status than Afrikaans guises. ${ }^{18}$ This result is in keeping with sociolinguistic stereotypes in South Africa more generally, where English is associated with relatively higher levels of overt prestige than Afrikaans (Vorster and Proctor 1976). This language effect, however, is conditioned by a significant interaction with /s/-quality, such that only those English guises that contain fronted /s/ are perceived as having significantly higher status. English guises without fronted /s/ are perceived as having comparable levels of status as the Afrikaans guises. Corrected pairwise

Table 5: Regression analysis of perceptions of Status component for female guises.

\begin{tabular}{lccrr}
\hline Fixed effects & Estimates & Std. Error & $\boldsymbol{t}$ & p-value \\
\hline Intercept & -0.104 & 0.072 & -1.442 & 0.149 \\
Language (ENGLISH) & 0.354 & 0.082 & 4.314 & 0.000 \\
Fronting (NON-FRONTED) & 0.136 & 0.081 & 1.678 & 0.094 \\
Language: Fronting & -0.571 & 0.116 & -4.948 & 0.000 \\
Random intercept: Respondent $(n=195) ;$ Log likelihood: -1000.711 & & \\
\hline
\end{tabular}

18 In Table 5, and in all regression tables that follow, analyses are based only on the responses of those listeners who rated the guises on all eight evaluation scales (some listeners, for example, provided no ratings for a particular scale, or no ratings for a particular guise). Thus, while 214 listeners participated in the experiment, for statistical modelling purposes (and in an effort to be as conservative as possible) we focus only on those who completed all aspects of the task. For female guises, analyses are based on the responses of 195 listeners; for male guises, they are based on the responses of 197 . 
comparisons further confirm that /s/-quality has a significant effect on perceptions of status for the English guises $(p=0.000)$ but not for the Afrikaans ones $(\mathrm{p}=0.141)$. The relevant effect is clearly visible in an examination of respondents' raw scores on the intelligent/not intelligent and educated/not educated scales, where we find an average score for perceived intelligence/education of 4.31 (out of 6) for non-fronted English guises and 4.69 for fronted English guises. This difference of 0.38 points on average is admittedly not very large, but it is nearly twice the difference observed between fronted and non-fronted Afrikaans guises (4.30 and 4.46, respectively). The results in Table 5 therefore indicate that /s/-fronting serves to cue perceived status for female voices in English, though it appears to carry no such meaning in Afrikaans.

Turning to perceptions on the gender/sexuality component, we find no significant effect of /s/-quality. There is a minor effect of language, whereby all English female guises are perceived as significantly less masculine and less lesbian than the Afrikaans female guises $(p=0.041)$. We have, however, no definitive interpretation for this finding. In addition to this main effect of language, there is evidence for a second main effect of respondent sex, such that male listeners rate all of the female guises (i.e., in both Afrikaans and English) as sounding more masculine and lesbian than the female listeners do $(p=0.002)$. Again, we have no conclusive interpretation of this finding, other than to suggest that it may reflect a relatively greater willingness on the part of male listeners to label a female speaker as sounding masculine and/or lesbian. In other words, it may be the case that female respondents find the voices to sound equally as masculine or lesbian as the male respondents, but they are simply less willing to explicitly label them as such. Though an intriguing possibility, we have no way to test this proposal in the current dataset and so just list it as a possibility. Overall then, the most important finding of the analysis of the gender/sexuality component is the lack of any significant effect of /s/-quality on listener perceptions. While we must always interpret negative results with caution, it is interesting that listeners show no evidence of sensitivity to /s/-fronting as a cue of gender/sexuality in the female guises, particularly given prior research that has shown a strong link between /s/ and gender in women's voices (e.g., Stuart-Smith 2007; Levon and Holmes-Elliott 2013). We note, however, a potential shortcoming of our method in this regard, which is that we never elicited perceptual reactions of perceived femininity directly. Rather, we only asked for ratings of perceived masculinity (versus non-masculinity) and lesbianness (versus non-lesbianness). That we did so may at least partially explain the lack of any significant effect of /s/-fronting on the gender/sexuality component for female guises. Added to this is the suspicion that in the absence of any direct elicitation of femininity, 
respondents may have transferred their perception of femininity of the guises to their ratings of other factors. This possibility will become clearer in the analyses and interpretations provided below.

Table 6: Regression analysis of perceptions of Urban component for female guises.

\begin{tabular}{lrrrr}
\hline Fixed effects & Estimates & Std. Error & $\boldsymbol{t}$ & p-value \\
\hline Intercept & -0.340 & 0.0678 & -5.019 & 0.000 \\
Language (ENGLISH) & 0.853 & 0.085 & 10.025 & 0.000 \\
Fronting (NON-FRONTED) & -0.037 & 0.084 & -0.436 & 0.663 \\
Language: Fronting & -0.239 & 0.120 & -1.995 & 0.047 \\
Random intercept: Respondent $(\mathrm{n}=$ 195); Log likelihood: -987.5 & & \\
\hline
\end{tabular}

The urban component for female guises, in contrast, shows a clear effect for /s/fronting (see Table 6). This effect emerges in the context of a significant interaction with language, which demonstrates that English guises overall are perceived as significantly more urban than Afrikaans guises $(p=0.000)$. If we consider the raw scores for ratings on the urban scale, we find that the female English guises receive an average rating of 4.31 (again, out of 6) while the Afrikaans guises receive an average rating of only 3.07. This difference in ratings conforms to predictions, and corresponds to the general assumption (or stereotype) that English speakers are highly concentrated in and associated with urban centers in South Africa, whereas white Afrikaans speakers are less so and have, traditionally, strong ties with rural areas. Recall, though, that the urban component is not comprised only of a perceived urban/country distinction; it also includes a strong correlation between urban-ness and dishonesty. The language effect in Table 6 is thus not simply a reflection of a perception about demographics, but also contains an implicit moral commentary on the English versus Afrikaans communities. Interestingly, and as noted above, this distinction between perceptions of English and perceptions of Afrikaans is influenced by /s/-fronting. While English guises are always rated as sounding more urban (and dishonest) than Afrikaans guises, this effect is heightened for fronted English guises (average urban rating $=4.63$ ) as opposed to non-fronted English guises (average urban rating $=3.99$ ). What this means is that, overall, /s/-fronting acts as a salient cue of urban-ness in English, though no such effect is evident in Afrikaans.

Finally, we also find a significant interaction between language and /s/fronting in perceptions of the fourth component, likeability (see Table 7). In contrast to the results described above, the likeability component is the only 
Table 7: Regression analysis of perceptions of Likeability component for women's guises.

\begin{tabular}{lrcrr}
\hline Fixed Effects & Estimates & Std. Error & $\boldsymbol{t}$ & p-value \\
\hline Intercept & 0.312 & 0.071 & 4.429 & 0.000 \\
Language (ENGLISH) & -0.600 & 0.083 & -7.220 & 0.000 \\
Fronting (NON-FRONT) & -0.222 & 0.082 & -2.699 & 0.007 \\
Language: Fronting & 0.373 & 0.117 & 3.192 & 0.001 \\
Random intercept: Respondent $(\mathrm{n}=195)$; Log likelihood: -1000.5 & & \\
\hline
\end{tabular}

one where /s/-fronting has a significant effect on perceptions in Afrikaans. Overall, female English guises receive an average rating on the laidback scale (which is the primary constituent of the likeability component) of 3.27, while Afrikaans guises receive an average rating of 3.63, indicating that listeners judge the Afrikaans guises as generally more likeable than the English ones $(p=0.000)$. When we consider the effect of $/ \mathrm{s} /$-fronting across languages, this pattern becomes somewhat more complex. For the English guises, average ratings of perceived likeability decrease as we move from the non-fronted guise (e.g., average laidback rating of 3.38) to the fronted guise (average laidback rating of 3.18). The difference in ratings between the guises is relatively small, but is nevertheless marginally significant (for the fronting effect among female English guises only, $\mathrm{p}=0.052$ ). In Afrikaans, in contrast, average ratings for perceived likeability increase in the presence of $/ \mathrm{s} /$-fronting, with, for example, average laidback ratings of 3.46 for non-fronted guises as compared to average ratings of 3.79 for fronted guises. This difference is highly significant $(\mathrm{p}=0.006)$, indicating that $/ \mathrm{s} /$-fronting cues enhanced perceptions of likeability (i.e., laidback and, to a lesser extent, friendly) in Afrikaans, while it appears to do the opposite in English.

Table 8: Observed effects of /s/-fronting for Female Guises.

\begin{tabular}{lllll}
\hline & Status & Gender/Sexuality & Urban & Likeability \\
\hline English & + & $(\mathrm{n} / \mathrm{a})$ & + & - \\
Afrikaans & $(\mathrm{n} / \mathrm{a})$ & $(\mathrm{n} / \mathrm{a})$ & $(\mathrm{n} / \mathrm{a})$ & + \\
\hline
\end{tabular}

Table 8 summarizes the effect of /s/-fronting for both English and Afrikaans female guises. In English, we see that /s/-fronting cues increased perceptions of speaker status and urban-ness, combined with a (marginally significant) decreased perception of speaker likeability. What emerges from these findings 
is the image of the English /s/-fronting woman as a person who is intelligent, educated and urban, but who is also simultaneously tense or uptight (i.e., not laidback) and somewhat morally questionable (i.e., dishonest). These perceptual findings parallel the results of earlier production-based research on this and related features (Bekker 2007; O'Grady and Bekker 2011), which has found fronting of the alveolar sibilants to be associated with the speech of young, upwardly-mobile (white) women in the wealthy suburbs north of Johannesburg. In that work, Bekker (2007) describes how this speech style is ideologically linked to a broader South African cultural stereotype called the kugel, originally stereotyped as a young, rich, normally Jewish woman who seeks a doctor or a lawyer as a husband (Lanham and Macdonald 1979), though in recent decades it has taken on a more generalized indexical meaning (Johnstone and Kiesling 2008) such that it now largely serves as a broad regional indicator of the rich (northern) suburbs of Johannesburg. ${ }^{19}$ We argue that our findings on the perceptions of /s/-fronting in the female English guises demonstrate that fronted /s/ serves as a perceptually salient cue of this kugel persona for our listeners. In Afrikaans, the only significant finding with respect to /s/-fronting is an increased perception of perceived likeability for fronted, as opposed to nonfronted, guises. While it is difficult to extrapolate from this finding alone, we would suggest that it could be linked to what is often termed the poppie stereotype in Afrikaans culture, or a less educated (or at least less focused on education) but friendlier and more easy-going woman; more generally the kind of women who typifies the "vanilla sexuality" mentioned in the quote at the end of the background section above. If this were indeed the case, then /s/-fronting would have the opposite indexical value for female voices in Afrikaans (less educated, more likeable) than in English (more educated, less likeable). Yet since we have no additional support for this claim, we can do no more than suggest it here and leave a fuller investigation of the potential meaning of /s/fronting among Afrikaans women to subsequent research. Overall then, we find evidence of distinct perceptual patterns for the Afrikaans versus English female guises, with /s/-fronting intuitively linked to the kugel persona in White South

19 The situation seems to be even more complex. Work by Du Plessis (2016) suggests that while the "kugel" accent may still be associated with status, wealth, etc. among certain groups, it is strongly dispreferred by upper-middle class, non-Jewish speakers in Johannesburg, who shy away from some of its most obvious characteristics (e.g., PRICE monophthongization). This might have to do with the fact that an important component of this accent is that it indexes social mobility (i.e., it is the accent of the nouveau riche), which is generally viewed as a socially undesirable trait by the established higher socioeconomic classes. 
African English (briefly leaving aside the various complications already mentioned above), while its status in White Afrikaans is less clear.

\subsection{Male guises}

Unlike for the female guises, we find parallel effects of /s/-fronting in Afrikaans and English for the male guises. Table 9 presents the results of the regression analysis for perceived status in the male guises (as before, higher ratings correspond to perceptions of greater levels of status). Recall that for male voices, the status component is comprised of perceptions of intelligence, education and, to a lesser extent, urban-ness. In Table 9, we find a main effect of language, such that English guises are perceived as significantly more statusful than Afrikaans guises $(p=0.000)$. This finding replicates what was found for the female guises, and is, once again, consonant with broader sociolinguistic ideologies in South Africa. In addition to this language effect, we find a further significant interaction between /s/-fronting and listener sex $(p=0.002)$. Pairwise comparisons reveal that this interaction effect is due to the influence of /s/-fronting on female listeners' perceptions of speaker status $(p=0.000)$, while fronting has no influence for the male listeners $(p=0.236)$. In fact, when we examine female listeners' average ratings for perceived intelligence, education and urbanness, we find a stepwise increase from the fronted Afrikaans guise (3.10), to the non-fronted Afrikaans guise (3.31), to the fronted English guise (3.39), up finally to the non-fronted English guise (3.62). What this indicates is that among female listeners there are independent main effects of language and fronting, such that Afrikaans is consistently perceived as less statusful than English and that fronted guises are consistently perceived as less statusful than non-fronted guises. For male listeners, in contrast, fronting is not shown to have an effect, and only the main effect of language

Table 9: Regression analysis of perceptions of Status component for male guises.

\begin{tabular}{lrrrr}
\hline Fixed effects & Estimates & Std. Error & $\boldsymbol{t}$ & p-value \\
\hline Intercept & -0.392 & 0.079 & -4.985 & 0.000 \\
Language (ENGLISH) & 0.446 & 0.056 & 7.947 & 0.000 \\
Fronting (NON-FRONTED) & 0.498 & 0.073 & 6.809 & 0.000 \\
Listener Sex (MALE) & -0.022 & 0.115 & -0.188 & 0.851 \\
Fronting: Listener Sex & -0.351 & 0.114 & -3.079 & 0.002 \\
Random intercept: Respondent $(\mathrm{n}=197)$; Log likelihood: -987.9 & & \\
\hline
\end{tabular}


holds. And while listener evaluations of perceived status for the male guises replicates the language effect found for the female guises, the fronting effect identified among female listeners (fronting linked to less status) is the opposite of what was found for the fronting effect in the female guises (where fronting was linked to more status). Moreover, while this fronting effect for female guises was present only in English, for male guises the exact same pattern occurs in both English and Afrikaans.

A somewhat similar pattern is evident in the findings for perceptions on the gender/sexuality component, though, unlike for the status component, language and /s/-fronting strongly influence listener perceptions throughout the sample. In Table 10, we see that perceptions of the gender/sexuality of male guises are conditioned by three independent effects: language $(\mathrm{p}=0.000), / \mathrm{s} /$-fronting $(\mathrm{p}=0.000)$ and listener sex $(\mathrm{p}=0.014)$. The listener sex effect indicates that male listeners are more likely to judge all guises as sounding more gay and less masculine than the female listeners are (recall that for this component, higher ratings correspond to increased perceptions of normative gender/sexuality). This finding reproduces the effect seen for perceived gender/sexuality in the female guises, where there too male listeners were shown to be more likely to rate the guises as having non-normative gender/sexuality. Above, we interpret this finding to indicate that female listeners are perhaps less willing to label a woman as sounding masculine or lesbian (or that male listeners are more willing to do so). Given the finding in Table 10, we suggest that this interpretation can be extended to cover gender/ sexuality more generally, such that the female listeners are less willing than the men to explicitly label a speaker as having a non-normative gender/ sexuality more broadly. While an explanation for why this may be the case goes beyond the scope of the current analysis, we note as a potentially intriguing pattern that there is a robust disparity in our dataset between female and male listeners in terms of their general tendency to associate a voice with non-normative gender/sexuality.

Table 10: Regression analysis of perceptions of Gender/Sexuality component for male guises.

\begin{tabular}{lrrrr}
\hline Fixed effects & Estimates & Std. Error & $\boldsymbol{t}$ & p-value \\
\hline Intercept & 0.083 & 0.075 & 1.115 & 0.266 \\
Language (ENGLISH) & -0.435 & 0.055 & -7.937 & 0.000 \\
Fronting (NON-FRONT) & 0.466 & 0.055 & 8.499 & 0.000 \\
Listener sex (MALE) & -0.245 & 0.098 & -2.483 & 0.014 \\
Random intercept: respondent $(\mathrm{n}=197) ;$ Log likelihood: -974.6 & & \\
\hline
\end{tabular}


Yet despite these overarching sex-based tendencies, we still find significant main effects of both language and /s/-fronting for judgments of perceived gender/ sexuality of the male guises among all listeners. In terms of language, English guises are perceived as being significantly less masculine/more gay than Afrikaans guises $(p=0.000)$. Raw scores on the masculine and (reversed) gay scales confirm this, with average values of 4.74 for the Afrikaans guises and 4.41 for the English guises. This small but significant effect corresponds to wider gendered stereotypes that circulate in South Africa, and that associate Englishspeaking men with a more effete, intellectual, urban elite and Afrikaans-speaking men with a more rural, virile lifestyle (cf. our sociohistorical discussion above). This is particularly true in Afrikaans communities, such as the ones from which our listener sample is taken. The main effect of language that we find here is therefore not surprising. For the fronting main effect, we find that non-fronted guises are perceived as significantly more masculine/less gay than their fronted counterparts $(\mathrm{p}=0.000)$. Once again, this pattern is confirmed by an examination of the average ratings on the masculine and (reversed) gay scales, where fronted guises receive an average value of 4.25 and non-fronted guises an average value of 4.91. Though we know of no other work on /s/-fronting among men in South Africa, our findings resonate with a growing body of research (including many of the studies in this issue) on the perceptual meanings of /s/ in men's voices crosslinguistically (e.g., Zimman 2013; Pharao et al. 2014). In this work, a consistent finding is an indexical association between /s/-fronting and perceptions of both gayness and reduced levels of masculinity in men. The results presented in Table 10 thus demonstrate the applicability of this more general indexical pattern to both White Afrikaans and WSAfE.

Finally, our analyses demonstrate that /s/-fronting has no effect on perceptions of the likeability component for male guises. The only factor shown to have an effect on perceived likeability is language, with English guises overall judged as significantly less likeable than Afrikaans guises $(p=0.000)$. This pattern replicates what was found for female guises, where English was also judged to be significantly less likeable than Afrikaans (though in that case there was also an additional interaction with /s/-fronting). That Afrikaans is perceived as more likeable among our listener population is to be expected, given that they are all L1 Afrikaans speakers and it is a fairly robust finding of language attitudes research that listeners associate higher degrees of social attractiveness to their own varieties as compared to others (e.g., Coupland and Bishop 2007). The lack of any effect of $/ \mathrm{s} /$-fronting, in contrast, is somewhat surprising, particularly given the fronting effect for perceptions of the male guises' status. Normally, status and likeability ratings mirror one another, and so we might have 
anticipated that female listeners, i.e., those who were sensitive to /s/-quality as a correlate of status in men's voices, would also have been sensitive to it as a potential cue of likeability. This, however, is not the case and instead all we find is a global language effect for perceptions of likeability.

Table 11: Observed effects of /s/-fronting for Male Guises.

\begin{tabular}{llll}
\hline & Status & Gender/Sexuality & Likeability \\
\hline English & $-^{+}$ & - & $(\mathrm{n} / \mathrm{a})$ \\
Afrikaans & $-^{+}$ & - & $(\mathrm{n} / \mathrm{a})$ \\
\hline
\end{tabular}

${ }^{\dagger}$ For female listeners only

Table 11 summarizes the results of the analyses of perceptions of /s/-fronting in the male guises. Contrary to what was found for the female guises (see Table 8), /s/-fronting appears to cue identical meanings in Afrikaans and in English for our listener population. In both cases, the presence of fronting causes listeners to judge the speaker as sounding significantly less masculine and more gay. As we note above, this finding replicates the results of research on /s/-fronting in numerous languages around the world. In addition to this gender/sexuality effect, for female listeners /s/-fronting is also negatively correlated with perceived speaker status. We suggest that the presence of this additional correlate of /s/-quality is an instantiation of a widely reported pattern whereby percepts of masculinity are linked to percepts of status (e.g., Campbell-Kibler 2011; Levon 2014). In other words, it is quite common to find that linguistic features that cue masculinity also serve to cue increased perceptions of speaker competence and social standing. A relationship between masculinity and status has often been accounted for in terms of stereotypical gender norms, which tend to view men as more status-ful than women, and more masculine men as more status-ful than less masculine men (e.g., Pleck et al. 1993). We argue that this previous analysis also applies here, such that the correlation between /s/-fronting and perceived status in our dataset in a sense derives from the correlation between /s/-fronting and normative male gender/sexuality. It remains an open question, however, why it is that in the current study only female respondents extend the gendered meaning of /s/fronting in this way. This issue notwithstanding, we claim that our results demonstrate a clear associated between /s/-quality and percepts of male gender (and male gender norms) in both Afrikaans and WSAfE. 


\section{The embedded nature of /s/-fronting in Afrikaans and WSAfE: Parallel innovation or sociolinguistic transfer?}

Having detailed the results of listeners' evaluations of /s/-fronting in the female and male guises separately, it is instructive to now consider these findings together in order to determine whether the feature appears to have a unified, underlying indexical meaning that can account for all the different perceptual patterns observed. In the English guises, we find that /s/-fronting cues perceptions of increased status, increased urban-ness and decreased likeability in a woman's voice, and decreased status and increased gayness in a man's. Based on this, we argue that /s/-fronting serves as a consistent index of femininity in WSAfE for the listeners in our sample. For the male guises, the interpretation is fairly straightforward: a percept of femininity cued by fronting results in a heightened judgment of gayness (and, correspondingly, decreased masculinity). We assume that this outcome is part of a more general stereotype that views gay male sexuality as inherently linked to femininity in men (e.g., Gaudio 1994). The additional finding that some listeners also downgrade perceptions of the speaker's status when /s/-fronting is present derives, we argue, from a related stereotype, alluded to above, that links normative masculinity with high levels of competence and status. Hence, a male voice that is perceived as sounding feminine is for various stereotypical reasons also perceived of as sounding gay and lower in status.

For the female English guises, the analysis is somewhat less direct since we find no effect of fronting on the gender/sexuality component itself. We nevertheless maintain that, in these cases too, fronting is understood by listeners to cue femininity, and that the reason we find no gender/sexuality effect is because we elicited responses to perceived masculinity and lesbianness only and not to perceived femininity (or at least not directly). What we suggest is happening here is that the indexation of femininity by /s/-fronting causes listeners to activate a stored representation of the kugel stereotype, and thus that the perceptual evaluations obtained reflect the traits listeners associate with this kugel persona. Put another way, when listeners in our sample encounter a percept of femininity in an English woman' voice, we claim that they interpret this as an instantiation of a particular female archetype in South Africa (i.e., the kugel) and rate the speaker accordingly. In short then, we argue that by interpreting /s/-fronting as a persistent cue of perceived femininity in English, we are able to provide a unified account of the range of evaluative reactions to the 
English guises described above. The key to our argument is that while the indexical meaning of /s/-fronting remains constant (i.e., femininity), how that meaning ultimately gets interpreted (and what attributes it becomes associated with) ultimately depends on the context in which the feature is embedded (i.e., a woman's or a man's voice) and the broader social stereotypes that inform how femininity is interpreted in these contexts.

Our analysis of the perceptual reactions to the Afrikaans guises is very much the same, though the empirical evidence to support our claims is admittedly weaker. Nevertheless, we propose that, like in English, /s/-fronting in White Afrikaans is a salient cue of femininity for the listeners in our sample. As before, our argument is straightforward in the case of the male guises, where we suggest that a percept of femininity indexed by /s/-fronting results in the relevant recordings being judged as gayer, less masculine and, for some, less statusful, due to the same sociolinguistic stereotypes that operate in English. In saying this we do not claim that male gender and sexuality are conceptualized in precisely the same fashion in both English and Afrikaans communities in South Africa, but rather that in this particular example the findings are analogous. Our interpretation becomes somewhat more tenuous, however, when we consider the female guises in Afrikaans, where the only significant effect observed is a perception of increased likeability in the presence of /s/-fronting. Above, we suggest that this likeability finding may result from /s/-fronting activating a poppie stereotype in the minds of listeners (i.e., the image of a friendly, laidback Afrikaans woman). If this suggestion is accurate, then it is fairly easy to draw a connection from /s/-fronting cueing femininity to the poppie persona being activated. Similar to our argument regarding the kugel stereotype in English, we propose that perceiving femininity in this context leads listeners to access a stored representation of a feminine Afrikaner archetype (the poppie), which, by extension, results in the observed boost to ratings on the likeability scale. While we concede that this analysis requires further empirical support, we maintain that it allows us to provide a unified account of the underlying meaning of /s/-fronting in Afrikaans. Ultimately, we therefore suggest that both in WSAfE and, more tentatively, in White Afrikaans, /s/-fronting is at its base an index of femininity.

To the extent that we accept the claim that there is a shared meaning of the feature in White Afrikaans and WSAfE, a number of potentially interesting questions arise. Though they are largely beyond the scope of our discussion here, we outline them briefly as a guide to possible future research in this area. Given that WSAfE and White Afrikaans are and have been in such close contact for so long (see sociohistorical background above), the question of the origin of the feature in each of the languages presents itself. It could be the case, for 
example, that /s/-fronting as a salient cue of femininity was originally a feature of English in South Africa that was at some point transferred into Afrikaans. ${ }^{20}$ We know from both empirical and anecdotal evidence that an indexical relationship between /s/-fronting and femininity exists in numerous varieties of English around the world (e.g., in the US: Munson et al. 2006; Levon 2006; CampbellKibler 2011; Zimman 2013; in England: Levon 2014; in Scotland: Stuart-Smith 2007; and in New Zealand: Starks and Allan 2003), and that the feature has existed in South African English for some time (Bekker 2007). It is therefore possible that /s/-fronting as an index of femininity in Afrikaans is a result of sociophonetic transfer from English, where what was borrowed was not only the linguistic feature itself but also its associated indexical meaning.

Yet we must be careful not to jump too quickly to a transfer-based argument since it is also entirely possible that the presence of /s/-fronting in Afrikaans is due to an independent language-internal process and has nothing to do with the fact that the feature also exists in WSAfE (Poplack and Levey 2010). In other words, we must identify positive evidence for /s/-fronting as a contact-derived feature before we can safely make any claim in this regard. Such evidence could potentially be found, for example, in historical descriptions of Afrikaans to see if any mention of the feature pre- or post-dates extensive contact with English. In practice, we surmise that such evidence would be difficult, if not impossible, to find since phonetic variables of this type are not often described in the historical record. A potentially more promising avenue of research would be to examine perceptions of the feature across a more varied listener sample; in particular, including respondents with differing degrees of contact with WSAfE. If /s/fronting in White Afrikaans were indeed a result of (recent) transfer, we would normally expect to find variation in listeners' judgments of the feature as a function of their exposure, and hence presumed knowledge, of the feature's meaning in English. In addition, we may wish to examine possible variation in both the perception and production of /s/-fronting as a function of listeners' attitudes to English. Given that borrowing from English into Afrikaans would presumably be a case of prestige-driven superstrate transfer (Sharma 2012), we would anticipate that those with more positive attitudes toward English would perceive, and potentially use, the feature quite differently than those with more negative views. In the absence of such evidence, we cannot rule out the possibility that /s/-fronting emerged as an index of femininity in both Afrikaans and

20 There is also, of course, the on-the-surface less likely possibility that /s/-fronting was transferred from Afrikaans to English. 
WSAfE independently, potentially based on some more universal or sound symbolic property of the feature (e.g., Ohala 1994). For the moment then, we hope simply to have demonstrated that /s/-fronting functions as a salient, though contextually-sensitive, cue of femininity in both WSAfE and Afrikaans, and leave a full investigation of the origins of this shared feature to subsequent research.

Acknowledgments: The authors would like to thank Kara Schultz, Deon du Plessis, Bertus van Rooy and Andries Coetzee for reading earlier versions of this article and for offering valuable commentary and suggestions.

\section{Appendix A. Stimuli}

Stimulus Passage - Afrikaans (Matthee 1984)

Vandat hy kan onthou, is Oupoot die mees gevreesde olifant in die Bos. Geen houtkapper het sonder respek van hom gepraat of sy spoor gekry en nie onmiddellik gekyk watter kant die wind waai nie.

Hy was veertien toe hy Oupoot vir die eerste keer gesien het. Baie dinge het met hom gebeur toe hy veertien geword het.

Die godsiekte het twee maande voor sy verjaarsdag deur die Bos getrek: masels, kinkhoes en plek-plek waterpokke. Magdalena moes eerste gaan lê. Toe Sara inval, het hul ma ook siek geword. Masels. Hy en sy pa en Jozef en ou Anneries het ver van die huis af kalander vir dwarslêers gewerk en van niks geweet nie.

Stimulus Passage - English (Matthee 2005)

As long as he could remember, Old Foot had been the most feared elephant in the Forest. No woodcutter spoke of him without respect or found his tracks without immediately looking to see which way the wind was blowing.

Saul was fourteen when he saw Old Foot for the first time. Many things happened to him when he was fourteen.

Two months before his birthday the godsickness came through the Forest: measels, whooping-cough and even chickenpox in some places. Magdalena was the first to go down with it. When Sara caught it their mother became ill, too. Measels. He and his father and Jozef and old Arno were working kalander for sleepers far from home and knew nothing of what was going on. 


\section{Appendix B. Rating scales}

English translations appear in parentheses. Only Afrikaans was used during the experiment.

\begin{tabular}{|c|c|c|c|c|c|c|c|}
\hline $\begin{array}{l}\text { Baie intelligent (very } \\
\text { intelligent) }\end{array}$ & $\square$ & $\square$ & $\square$ & $\square$ & $\square$ & $\square$ & $\begin{array}{l}\text { Glad nie intelligent nie (not at } \\
\text { all intelligent) }\end{array}$ \\
\hline $\begin{array}{l}\text { Baie vriendelik (very } \\
\text { friendly) }\end{array}$ & $\square$ & $\square$ & $\square$ & $\square$ & $\square$ & $\square$ & Onvriendelik (not at all friendly) \\
\hline $\begin{array}{l}\text { Baie oneerlik (very } \\
\text { dishonest) }\end{array}$ & $\square$ & $\square$ & $\square$ & $\square$ & $\square$ & $\square$ & Baie eerlik (very honest) \\
\hline $\begin{array}{l}\text { Baie manlik(very } \\
\text { masculine) }\end{array}$ & $\square$ & $\square$ & $\square$ & $\square$ & $\square$ & $\square$ & $\begin{array}{l}\text { Glad nie manlik nie (not at all } \\
\text { masculine) }\end{array}$ \\
\hline $\begin{array}{l}\text { Bly in 'n stad (lives in a } \\
\text { city) }\end{array}$ & $\square$ & $\square$ & $\square$ & $\square$ & $\square$ & $\square$ & $\begin{array}{l}\text { Bly op die platteland (lives in the } \\
\text { country) }\end{array}$ \\
\hline $\begin{array}{l}\text { Beslis gay/lesbies } \\
\text { (definitely gay/lesbian) }\end{array}$ & $\square$ & $\square$ & $\square$ & $\square$ & $\square$ & $\square$ & $\begin{array}{l}\text { Beslis nie gay/lesbies nie } \\
\text { (definitely not gay/lesbian) }\end{array}$ \\
\hline $\begin{array}{l}\text { Baie geleerd (very } \\
\text { educated) }\end{array}$ & $\square$ & $\square$ & $\square$ & $\square$ & $\square$ & $\square$ & $\begin{array}{l}\text { Glad nie geleerd nie (not at all } \\
\text { educated) }\end{array}$ \\
\hline $\begin{array}{l}\text { Baie gemoedelik ("laid- } \\
\text { back") (very laidback) }\end{array}$ & $\square$ & $\square$ & $\square$ & $\square$ & $\square$ & $\square$ & $\begin{array}{l}\text { Glad nie gemoedelik ("laid- } \\
\text { back") nie (not at all laidback) }\end{array}$ \\
\hline
\end{tabular}

\section{References}

Bekker, lan. 2003. Using historical data to explain language attitudes: A South African case study. AlLA Review 16. 62-77.

Bekker, Ian. 2007. Fronted /s/ in General White South African English. Language Matters 38(1). 46-74.

Campbell-Kibler, Kathryn. 2007. Accent, (ING), and the social logic of listener perceptions. American Speech 82(1). 32-64.

Campbell-Kibler, Kathryn. 2011. Intersecting variables and perceived sexual orientation in men. American Speech 86(1). 52-68.

Coupland, Nikolas \& Hywel Bishop. 2007. Ideologised values for British accents. Journal of Sociolinguistics 11(1). 74-93.

Davies, Rebecca. 2009. Afrikaners in the new South Africa: Identitypolitics in a globalised economy. London: Taurus Academic Studies.

Du Plessis, Deon. 2016. Regionality in White South African English: An acoustic dialectometric investigation. Potchefstroom: North-West University MA thesis.

Gaudio, Rudolf. 1994. Sounding gay: Pitch properties in the speech of gay and straight men. American Speech 69(1). 30-57.

Giliomee, Hermann. 2003. The Afrikaners: Biography of a people. Cape Town: Tafelberg. 
Hammond, Nicol. 2010. The gendered sound of South Africa: Karen Zoid and the performance of nationalism in the New South Africa. Yearbook for Traditional Music 42. 1-20.

Johnstone, Barbara \& Scott F. Kiesling. 2008. Indexicality and experience : Exploring the meanings of /aw/-monophthongization in Pittsburgh. Journal of Sociolinguistics 12(1). 5-33.

Lambert, Wallace E., Richard C. Hodgson, Robert C. Gardner \& Stanley Fillenbaum. 1960. Evaluational reactions to spoken languages. Journal of Abnormal and Social Psychology 60(1). 44-51.

Lanham, Len W. \& Carol A. Macdonald. 1979. The standard in South African English and its social history. Heidelberg: Julius Groot Verlag.

Levon, Erez. 2006. Hearing "gay": Prosody, interpretation and the affective judgments of men's speech. American Speech 81(1). 56-78.

Levon, Erez. 2007. Sexuality in context: Variation and the sociolinguistic perception of identity. Language in Society 36(4). 533-544.

Levon, Erez. 2014. Categories, stereotypes and the linguistic perception of sexuality. Language in Society 43(5). 539-566.

Levon, Erez \& Sophie Holmes-Elliott. 2013. East end boys and west end girls : /s/-fronting in southeast England. University of Pennsylvania Working Papers in Linguistics 19(2). 111-120.

Matthee, Dalene. 1984. Kringe in 'n bos. Cape Town: Tafelberg.

Matthee, Dalene. 2005. Circles in a forest. Johannesburg: Penguin.

McClintock, Anne. 1993. Family feuds: Gender, nationalism and the family. Feminist Review 44. 61-80.

Mesthrie, Rajend. 2010. Socio-phonetics and social change: Deracialisation of the GOOSE vowel in South African English. Journal of Sociolinguistics 14(1). 3-33.

Munson, Benjamin, Elizabeth C. McDonald, Nancy L. DeBoe \& Aubrey R. White. 2006. The acoustic and perceptual bases of judgments of women and men's sexual orientation from read speech. Journal of Phonetics 34(2). 202-240.

O'Grady, Cathleen \& Ian Bekker. 2011. Dentalisation as a regional indicator in General South African English: An acoustic analysis of /z/, /d/ and /t/. South African Linguistics and Applied Language Studies 29(1). 77-88.

Ohala, John. 1994. The biological bases of sound symbolism. In Leanne Hinton, Johanna Nichols \& John Ohala (eds.), Sound symbolism, 222-236. Cambridge: Cambridge University Press.

Pharao, Nicolai, Marie Maegaard, Janus Møller \& Tore Kristiansen. 2014. Indexical meanings of $[\mathrm{s}+]$ among Copenhagen youth: Social perception of a phonetic variant in different prosodic contexts. Language in Society 43(1). 1-31.

Pienaar, Kiran \& Ian Bekker. 2006. Invoking the feminine physical ideal: Bitch-slapping, she-men and butch girls. Southern African Linguistics and Applied Language Studies 24(4). 437-447.

Pienaar, Kiran \& Ian Bekker. 2007. The body as a site of struggle: Oppositional discourses of the disciplined female body. Southern African Linguistics and Applied Language Studies 25(4). 539-555.

Pisani, Kobus, Du. 2001. Puritanism transformed: Afrikaner masculinities in the apartheid and post-apartheid period. In Robert Morrell (ed.), Changing men in Southern Africa, 157-176. Pietermaritzburg: University of Natal Books. 
Pleck, Joseph, Freya Sonenstein \& Ku. Leighton. 1993. Masculinity ideology and its correlates. In Stuart Oskamp \& Mark Constanzo (eds.), Gender issues in contemporary society, 85-110. London: Sage.

Poplack, Shana \& Stephen Levey. 2010. Contact-induced grammatical change: A cautionary tale. In Peter Auer \& Jürgen Erich Schmidt (eds.), Language and space: An international handbook of linguistic variation, 391-419. Berlin \& New York: Walter de Gruyter.

Pretorius, Deirdre. 2013. The visual representation of masculinities in Huisgenoot Tempo magazine. Communicatio: South African Journal for Communication Theory and Research 39(2). 210-232.

Sharma, Devyani. 2012. Shared features in New Englishes. In Raymond Hickey (ed.), Areal features of the Anglophone world, 211-232. Berlin \& Boston: De Gruyter Mouton.

Starks, Donna \& Scott Allan. 2003. What comes before $t$ ? Nonalveolar $s$ in Auckland. Journal of English linguistics 31(3). 273-280.

Stuart-Smith, Jane. 2007. Empirical evidence for gendered speech production: /s/ in Glaswegian. In Jennifer Cole \& Jose Hualde (eds.), Laboratory Phonology 9: Phonology and phonetics, 65-86. Berlin \& New York: Mouton de Gruyter.

Vorster, Jan \& Leslie Proctor. 1976. Black attitudes to "white” languages in South Africa: A pilot study. The Journal of Psychology: Interdisciplinary and applied 92(1). 103-108.

Zimman, Lal. 2013. Hegemonic masculinity and the variability of gay-sounding speech. Journal of Language and Sexuality 2(1). 1-39. 